\title{
Aspectos epidemiológicos e clínico-laboratoriais da Diabetes Mellitus em cães
}

\author{
Epidemiologic and clinical-pathological features of canine Diabetes Mellitus
}

Álan Gomes Pöppl ${ }^{1} \&$ Félix Hilario Díaz González²

\begin{abstract}
RESUMO
A diabetes mellitus canina vem aumentando no sul do Brasil. Na etiologia, obesidade, vida sedentária e estresse são os principais fatores. Após o diagnóstico recomenda-se identificar doenças que possam causar intolerância à glucose. Para este fim, perfil bioquímico sérico, urinálise e hemograma devem ser determinados. O objetivo deste trabalho foi identificar as principais alterações clínico-patológicas de cães diabéticos e estabelecer valores de referência para fructosamina. Dez cadelas atendidas por um hospital veterinário universitário do sul do Brasil foram incluídas no estudo para realizar hemograma, testes bioquímicos e urinálise. Foram dosados no soro creatinina, uréia, ALT, AST, GGT, ALP, albumina, proteína total, globulinas, colesterol, triglicerídeos, $\beta$-OH-butirato, amilase pancreática, glicose e fructosamina. Vinte e cinco cães sadios foram usados como controle. O hemograma mostrou leucocitose em $30 \%$ dos cães diabéticos. Foi observada glicosúria em todos os cães. Proteinúria (50\%), cetonúria (40\%) e alta densidade urinária (30\%) foram as maiores alterações da urina dos animais diabéticos. As concentrações de glicose e colesterol estiveram acima dos valores de referência em todos os diabéticos. Os triglicerídeos foram mais altos, comparados com o grupo controle, em $90 \%$ dos cães diabéticos. Altos valores de proteína total (70\%), FAS (70\%), GGT (50\%), ALT e $\beta$-OH-butirato (40\%) foram observados nos cães com diabetes. A concentração sérica de fructosamina nos animais do grupo controle foi de $1.53 \mathrm{mmol} / \mathrm{L} \pm 0.27$ e nos diabéticos de $3.24 \mathrm{mmol} / \mathrm{L} \pm 1.16$.
\end{abstract}

Descritores: diabetes mellitus, cães, fructosamina, fatores predisponentes.

\section{ABSTRACT}

Canine diabetes mellitus has increased in southern Brazil. In the etiology, obesity, sedentary life and stress appear to be the main factors. After diagnosis is recommended to identify concurrent diseases that cause glucose intolerance. For this purpose, serum biochemical profile, urinalysis and complete blood count (CBC) must be determined. The aim of this study was to identify the most common clinical pathological changes in diabetic dogs from an university veterinary hospital in southern Brazil, and to establish fructosamine reference values. Ten diabetic female dogs attended at the veterinary hospital were included in this study to perform $\mathrm{CBC}$, biochemical assays and urinalysis. Creatinine, urea, ALT, AST, GGT, ALP, albumin, total protein, globulins, cholesterol, triglycerides, $\beta$-OH-butyrate, pancreatic amylase, glucose and fructosamine were measured in serum. Twenty-five healthy dogs were used as control for values. CBC showed leucocytosis in $30 \%$ of diabetic dogs. Glycosuria was observed in all dogs. Proteinuria (50\%), ketonuria (40\%) and high urine density in $30 \%$ of the animals, were the main alterations of urine in diabetic dogs. Serum glucose and cholesterol concentrations were above reference values in all diabetic dogs. Triglycerides were higher than control dogs in $90 \%$ of diabetic dogs. High values of total protein (70\%), ALP (70\%), GGT (50\%), ALT and $\beta$-OH-butyrate (40\%) were observed in diabetic dogs. Control group had a mean fructosamine concentration of $1.53 \mathrm{mmol} / \mathrm{L} \pm 0.27$. In diabetic dogs the fructosamine average was $3.24 \mathrm{mmol} / \mathrm{L} \pm 1.16$.

Key words: diabetes mellitus, dogs, fructosamine, predisposing factors. 


\section{INTRODUÇÃO}

A Diabetes Mellitus (DM) é uma doença crônica sistêmica decorrente de uma deficiência relativa ou absoluta de insulina [25]. Virtualmente, todos os cães diabéticos apresentam, no momento do diagnóstico, Diabetes Mellitus Insulino-Dependente (DMID) [34]. A maior incidência ocorre em fêmeas com mais de sete anos de idade [14]. Diversos fatores predispõem ao desenvolvimento da doença, sendo os mais importantes insulite imunomediada, pancreatite, obesidade, antagonismos hormonais (hiperadrenocorticismo, diestro, acromegalia), fármacos (glicocorticóides, estreptozootocina e aloxano), infecções, doenças intercorrentes (insuficiência renal, doença cardíaca), hiperlipidemia, amiloidose nas ilhotas pancreáticas e predisposição genética [5]. A prevalência de DM vem aumentando consideravelmente nos últimos anos e uma das causas atribuídas a este aumento é a maior prevalência de obesidade nos cães [16,17]. Entretanto, alguns autores não consideram a obesidade como fator de risco para o desenvolvimento de DM [7].

O objetivo deste trabalho foi estudar alguns aspectos epidemiológicos e clínico-patológicos presentes em uma população de cães diabéticos, a fim de identificar fatores predisponentes e alterações clínicolaboratoriais mais frequientes.

\section{MATERIAIS E MÉTODOS}

Foi realizado um estudo retrospectivo, de janeiro de 2000 a outubro de 2004, em cães com diagnóstico de DM atendidos em um hospital veterinário. Os proprietários dos pacientes responderam um questionário para verificar fatores predisponentes envolvidos no desenvolvimento da doença, sendo avaliados aspectos de raça, idade, sexo, sinais clínicos que motivaram o atendimento, tipo de alimentação, tratamentos, ganho de peso, estro, doenças intercorrentes, presença de cataratas e cetoacidose diabética no momento do diagnóstico. Também foi verificada a evolução dos casos após o diagnóstico. Foram utilizados dados de 20 cães com diagnóstico de DM para este estudo. No momento da entrevista os proprietários eram convidados a levar seus animais ao hospital para coleta de sangue e urina para determinar o perfil clínico-patológico dos animais. Amostras de sangue foram colhidas em tubos com EDTA $10 \%$ para hemograma e em tubos sem anticoagulante para análises bioquímicas. O soro obtido por centrifugação foi conservado a $-20^{\circ} \mathrm{C}$ até a realização das análises. As coletas de urina foram realizadas por micção natural ou cateterização, mantendo a urina refrigerada $\left(5^{\circ} \mathrm{C}\right)$ até sua análise, efetuada em no máximo duas horas após a coleta. Vinte e cinco cães sadios foram usados como controle para obter valores de referência de triglicerídeos e fructosamina.

A quantidade total de eritrócitos, leucócitos e hemoglobina foi determinada por diluição do sangue e leitura em contador automático ${ }^{1}$. O hematócrito foi obtido por centrifugação do sangue total em tubo capilar (10.000 rpm por 5 minutos). Os valores de VGM e CHGM foram calculados [39]. A leucometria diferencial foi determinada por leitura de esfregaço sangüíneo corado pelo método Panótico rápido. $\mathrm{Na}$ análise da urina, foi determinada a densidade com refratômetro e o exame químico com uso de tiras reagentes ${ }^{2}$. O exame do sedimento urinário foi realizado após centrifugação de $10 \mathrm{ml}$ de urina $(1.500 \mathrm{rpm}$ por 10 minutos) e observação ao microscópio óptico (400x). Todas as análises bioquímicas foram realizadas por espectrofotometria com kits diagnósticos ${ }^{3}$.

\section{RESULTADOS}

\section{Aspectos clínico-epidemiológicos}

Durante o período estudado, houve uma prevalência de 1 caso de DM para 865 consultas $(0,11 \%$ da população atendida). Metade dos cães com DM eram sem raça definida (SRD) e $25 \%$ eram Poodle. Houve um caso (5\%) em cada uma das seguintes raças: Cocker, Dog Alemão, Fox, mestiço Rottweiler x Poodle e mestiço Pincher x Fox. Dos vinte animais selecionados para o estudo, dezenove (95\%) eram fêmeas. A idade com que os pacientes desenvolveram a doença variou de 2 a 15 anos (média 10,45 $\pm 3,16$ anos) com pico de prevalência aos 10 anos. Da população inicial de 20 pacientes, 14 proprietários responderam ao questionário. A Tabela 1 apresenta os principais sinais clínicos que motivaram a consulta pelos proprietários. A poliúria foi o sinal mais freqüente.

Ao diagnóstico, 50\% dos pacientes eram alimentados com ração comercial e comida caseira, $28,6 \%$ com comida caseira e $21,43 \%$ com ração comercial. Onze proprietários $(78,6 \%)$ forneciam petiscos na forma de pães, biscoitos, doces e chocolates.

Uso anterior de corticóides foi relatado por $31,71 \%$ dos proprietários. Três proprietários $(21,43 \%)$ relataram uso de injeções anticoncepcionais. Nove das 13 pacientes fêmeas $(69,2 \%)$, haviam entrado no cio até dois meses antes do diagnóstico de DM. 


\begin{tabular}{lcc} 
Tabela 1. Prevalência dos sinais clínicos que motivaram a procura pelo veterinário. \\
\hline Sinal Clínico & Número de Casos & Porcentagem \\
\hline Poliúria & 12 & 85,7 \\
Polidipsia & 9 & 64,3 \\
Perda de peso & 7 & 50,0 \\
Anorexia & 5 & 35,7 \\
Vômitos & 5 & 35,7 \\
Polifagia & 4 & 28,6 \\
Apatia & 4 & 28,6 \\
Catarata/Cegueira abrupta & 3 & 21,4 \\
Outros & 2 & 14,3 \\
\hline
\end{tabular}

Nove proprietários $(69,2 \%)$ consideravam seus cães gordos, obesos ou com excesso de peso corporal. O mesmo percentual relatou que seus cães tinham uma rotina de exercícios diários, envolvendo caminhadas e alto nível de atividade. Seis proprietários $(42,8 \%)$ consideravam seus cães nervosos, estressados ou ansiosos.

Onze proprietários $(71,4 \%)$ relataram doenças anteriores ou intercorrentes ao diagnóstico, estando as neoplasias presentes em $42,8 \%$ dos casos e otite crônica em $14,3 \%$ dos casos. Onze animais $(78,6 \%)$ apresentavam cataratas no momento do diagnóstico, enquanto que cinco animais $(35,7 \%)$ foram considerados cetoacidóticos no momento do diagnóstico, avaliado pela presença de vômitos e anorexia.

Dos catorze pacientes com informações, oito deles $(57,1 \%)$ estão convivendo com a doença, com tempo de sobrevida após o diagnóstico variando de 1 semana até 8 anos (média de 1,55 anos). Dos seis animais que foram a óbito $(42,86 \%)$, três morreram por complicações da diabetes $(21,4 \%)$ entre 4 e 9 meses após o diagnóstico e nos três restantes $(21,4 \%)$ foi realizada eutanásia devido ao sofrimento do animal entre 4 e 7 meses após o diagnóstico.

\section{Aspectos de patologia clínica}

Dos vinte animais diabéticos participantes do estudo, dez proprietários aceitaram a realização dos perfis hematológicos, urinários e bioquímicos de seus animais. Os resultados constam nas Tabelas 2, 3 e 4 . O hemograma mostrou leucocitose leve em dois pacientes devido a um processo infeccioso intercorrente e mono-citose em outro paciente. Foi detectada densidade urinária aumentada (>1.040) em 50\% dos casos e glicosúria em 90\%. Foi observada cetonúria em $40 \%$ dos casos. As concentra- ções séricas de glicose e colesterol estiveram acima dos valores de referência em todos os animais diabéticos. Os triglicerídeos foram mais altos, comparados com o grupo controle, em $90 \%$ dos cães diabéticos. Foram achados altos valores de proteína total e FAS em $70 \%$ dos cães diabéticos, de GGT em $50 \%$ e de ALT e $\beta$-OHbutirato em $40 \%$ dos cães com diabetes. A concentração sérica de fructosamina nos animais do grupo controle foi de $1.53 \mathrm{mmol} / \mathrm{L} \pm 0.27$ e nos cães diabéticos de $3.24 \mathrm{mmol} / \mathrm{L} \pm 1.16$.

\section{DISCUSSÃO}

\section{Aspectos clínico-epidemiológicos}

A prevalência de DM em cães é relatada entre 1:100 e 1:500 (0,2 a 1\%) [25,27]. Em um período de 30 anos foi relatada uma prevalência de 1:270 [14]. No presente trabalho, observou-se uma baixa prevalência de DM, talvez em decorrência das diferenças entre as populações caninas estudadas. Atualmente, o modo de vida dos animais, que resulta em aumento de peso, decréscimo de atividades físicas, aumento de estresse psicológico e maior expectativa de vida deverá causar um dramático aumento na incidência de DM [27].

A raça Poodle é uma das raças com maior probabilidade de desenvolver DM, sendo que os cruzamentos seletivos dos três tipos de Poodle diminui a predisposição do Poodle standard à DM e predispõe os Poodle toy e miniatura $[15,16]$. Das outras raças com diagnóstico de DM encontradas neste estudo, apenas o Fox está entre os cães com maior risco de diabetes [14]. É citada predisposição familiar dos Rottweiler ao desenvolvimento de DM [7] e uma maior prevalência na raça Pinscher [12]. 
Tabela 2. Valores médios, desvio padrão, mínimo e máximo e intervalo de referência para os parâmetros hematológicos mensurados em cães diabéticos $(\mathrm{n}=10)$.

\begin{tabular}{|c|c|c|c|c|c|}
\hline Parâmetro (unidade) & Média & $\begin{array}{l}\text { Desvio } \\
\text { padrão }\end{array}$ & $\begin{array}{l}\text { Valor mínimo } \\
\text { e máximo }\end{array}$ & $\begin{array}{l}\text { Intervalo de } \\
\text { referência [38] }\end{array}$ & $\begin{array}{l}\text { Porcentual } \\
\text { alterado } \\
\text { (tendência) }\end{array}$ \\
\hline Eritrócitos $\left(\mathrm{x} 10^{6} / \mathrm{mm}^{3}\right)$ & 6,20 & 0,82 & $5,13-7,15$ & $5,5-8,5$ & $10(\downarrow)$ \\
\hline Hematócrito (\%) & 42,6 & 5,66 & $33-49$ & $37-55$ & 0 \\
\hline Hemoglobina (g/dl) & 14,9 & 2,02 & $11-17$ & $12-18$ & 0 \\
\hline $\operatorname{VCM}(\mathrm{fl})$ & 68,12 & 4,19 & $62-75,5$ & $60-77$ & 0 \\
\hline $\mathrm{CHCM}(\%)$ & 34,92 & 1,55 & $32,6-37,4$ & $31-36$ & $10(\uparrow)$ \\
\hline Leucócitos (cél x103/mm³) & 11.835 & $6.840,2$ & $6.076-25.334$ & $6.000-17.000$ & $20(\uparrow)$ \\
\hline Bastonados (cél//mm³) & 680,8 & $1.401,7$ & $0-4.541$ & $0-500$ & $30(\uparrow)$ \\
\hline Segmentados (cél/mm³) & 8.727 & 5.128 & $4.222-19.950$ & $3.000-11.000$ & $20(\uparrow)$ \\
\hline Basófilos (cél/mm³) & 0 & 0 & 0 & 0 & 0 \\
\hline Eosinófilos (cél/mm³) & 538,3 & 397 & $89-1.309$ & $100-1200$ & $10(\uparrow)$ \\
\hline Monócitos (cél/mm³) & 773,7 & 658 & $240-2.390$ & $100-1300$ & $20(\uparrow)$ \\
\hline Linfócitos (cél/mm³) & $1.375,4$ & 886 & $0-2.868$ & $1.000-5.000$ & $20(\downarrow)$ \\
\hline
\end{tabular}

Tabela 3. Valores médios, desvio padrão, mínimo e máximo e intervalo de referência para os parâmetros urinários mensurados em cães diabéticos $(n=10)$.

\begin{tabular}{|c|c|c|c|c|c|}
\hline Parâmetro (unidade) & Média & $\begin{array}{l}\text { Desvio } \\
\text { padrão }\end{array}$ & $\begin{array}{l}\text { Valor mínimo } \\
\text { e máximo }\end{array}$ & $\begin{array}{l}\text { Intervalo de } \\
\text { referência [1] }\end{array}$ & $\begin{array}{l}\text { Porcentual } \\
\text { alterado } \\
\text { (tendência) }\end{array}$ \\
\hline Densidade específica & 1.034 & 15,07 & $1.025-1.052$ & $1.015-1.045$ & $30(\uparrow)$ \\
\hline Glicose* & 3,4 & 1,34 & $0-4$ & 0 & $90(\uparrow)$ \\
\hline Cetonas $^{*}$ & 0,9 & 1,44 & $0-4$ & 0 & $40(\uparrow)$ \\
\hline Bilirrubina* & 0,20 & 0,42 & $0-1$ & $0-1$ & 0 \\
\hline Sangue oculto* & 0,2 & 0,42 & $0-1$ & 0 & $20(\uparrow)$ \\
\hline Proteína* & 0,5 & 0,53 & $0-1$ & $0-1$ & $50(\uparrow)$ \\
\hline Nitritos* & 0 & 0 & 0 & 0 & 0 \\
\hline Bactérias* & 1,42 & 0,97 & $1-4$ & $1-2$ & $10(\uparrow)$ \\
\hline $\mathrm{pH}$ & 5,75 & 0,84 & $5-7,5$ & $5,0-7,5$ & 0 \\
\hline Urobilinogênio (UE/100ml) & 0,2 & 0 & 0,2 & 0 & $100(\uparrow)$ \\
\hline Células epiteliais (/campo) & 3 & 2,3 & $1-7$ & $0-1$ & $20(\uparrow)$ \\
\hline Leucócitos (/campo) & 1,11 & 0,92 & $0-2$ & $0-7$ & 0 \\
\hline Eritrócitos (/campo) & 3 & 3,39 & $0-10$ & $0-7$ & $20(\uparrow)$ \\
\hline
\end{tabular}




\begin{tabular}{|c|c|c|c|c|c|}
\hline Parâmetro (unidade) & Média & $\begin{array}{l}\text { Desvio } \\
\text { padrão }\end{array}$ & $\begin{array}{l}\text { Valor mínimo } \\
\text { e máximo }\end{array}$ & $\begin{array}{l}\text { Intervalo de } \\
\text { referência }\end{array}$ & $\begin{array}{l}\text { Porcentual } \\
\text { alterado } \\
\text { (tendência) }\end{array}$ \\
\hline Creatinina $(\mathrm{mg} / \mathrm{dl})^{*}$ & 1,03 & 0,31 & $0,4-1,33$ & $0,9-2,1$ & 0 \\
\hline Uréia $(\mathrm{mg} / \mathrm{dl})^{*}$ & 30,5 & 17,4 & $12,2-71,3$ & $20-44,7$ & $10(\uparrow)$ \\
\hline $\operatorname{ALT}(\mathrm{U} /)^{\star}$ & 129,8 & 155,1 & $25,6-503$ & $<73,3$ & $40(\uparrow)$ \\
\hline AST $(U / I)^{\star *}$ & 54,5 & 45,3 & $17,6-153,6$ & $<66$ & $20(\uparrow)$ \\
\hline $\mathrm{GGT}\left(\mathrm{U} / \mathrm{I}^{* *}\right.$ & 10,1 & 7,12 & $4,3-24,3$ & $<6,4$ & $50(\uparrow)$ \\
\hline FAS $(\mathrm{U} /)^{*}$ & 741,5 & 1098,6 & $43-3495$ & $<81,9$ & $70(\uparrow)$ \\
\hline Albumina $\left(\mathrm{g} / \mathrm{l}^{*}\right.$ & 34,1 & 4,22 & $29,1-43,1$ & $21-33$ & $40(\uparrow)$ \\
\hline Proteínas totais $(\mathrm{g} / \mathrm{l})^{*}$ & 76,4 & 9,01 & $57,3-85,6$ & $60-74$ & $70(\uparrow)$ \\
\hline Globulinas $(g / l)^{*}$ & 42 & 7,2 & $28,1-51,2$ & $32-51$ & $30(\uparrow)$ \\
\hline Colesterol (mg/dl)* & 433,8 & 153,6 & $215-783,41$ & $105,6-205$ & $100(\uparrow)$ \\
\hline Triglicerídeos $(\mathrm{mg} / \mathrm{dl})^{\star \star \star}$ & 268,42 & 187,7 & $119,7-535,9$ & $20-112$ & $90(\uparrow)$ \\
\hline$\beta$-OH-butirato $(\mathrm{mmol} / \mathrm{L})^{\star *}$ & 1,54 & 1,63 & $0,1-3,4$ & $0,24-0,36$ & $40(\uparrow)$ \\
\hline Amilase $(U / l)^{\star *}$ & 498,7 & 171,8 & $280,4-740,6$ & $<700$ & 0 \\
\hline Glicose $(\mathrm{mg} / \mathrm{dl})^{*}$ & 401,13 & 131,6 & $248,5-564$ & $76,2-134,8$ & $100(\uparrow)$ \\
\hline Fructosamina $(\mathrm{mmol} / \mathrm{L})^{\star \star \star}$ & 3,23 & 1,27 & $1,74-4,92$ & $1,1-1,9$ & $80(\uparrow)$ \\
\hline
\end{tabular}

A idade ao diagnóstico de DM encontrada (pico de incidência aos 10 anos) aproxima-se da citada por outros autores: picos de prevalência entre 7 e 9 anos [12] e entre 10 e 15 anos [14].

As fêmeas caninas têm duas vezes mais probabilidade de desenvolver DM que os machos [6,13], o que está relacionado com o antagonismo crônico à insulina sofrido pelas cadelas durante o diestro [31,32]. No presente estudo observou-se uma prevalência quase trinta vezes maior em fêmeas que em machos.

Os sinais clínicos de DM encontrados neste trabalho concordam com os citados por outros autores, embora com diferente proporção. Cita-se polidipsia em 96\% dos casos, poliúria em $77 \%$, perda de peso em $44 \%$, vômitos em $38 \%$, apatia em $37 \%$, anorexia em $25 \%$ e polifagia em $19 \%$ dos casos [13]. Este trabalho encontrou a poliúria como sinal clínico mais freqüente, porém a catarata também aparece como sinal que levou à procura do veterinário em $21 \%$ dos casos. Em um estudo retrospectivo de 200 casos de cães diabéticos, somente $14,4 \%$ dos pacientes apresentaram catarata no momento do diagnóstico, sendo que a maioria dos cães desenvolveu esta alteração entre 5 e 6 meses após o diagnóstico de DM e cerca de $80 \%$ dos cães desenvolveram cataratas até os 16 meses após o diagnóstico [2]. No presente estudo, 78,5\% dos animais já haviam desenvolvido ou estavam iniciando o processo de formação de cataratas no momento do diagnóstico.

A cetoacidose, presente em cerca de $35 \%$ dos casos do presente estudo, surge depois que os proprietários falham em identificar os sinais clínicos da doença, situação eventualmente acompanhada da formação de cataratas [7]. Cerca de 40\% dos cães com DM ao atendimento apresentam cetoacidose [7], proporção semelhante à observada no presente estudo.

Apesar de 32\% dos proprietários admitirem que o animal já havia recebido tratamentos com corticosteróides, nenhuma relação causal com o diagnóstico de DM foi evidenciada. O uso prolongado de corticóides em cães suscetíveis pode resultar em DM [26]. Uma proporção menor dos proprietários $(21 \%)$ relatou uso de progestágenos nas pacientes. Muitos casos de neoplasias mamárias concomitantes à DM apresentavam histórico de uso de progestágenos como inibidores de ciclo estral [32]. A hiperplasia endometrial cística e a piometra causada por progestágenos [5] prejudicam 
a homeostase da glicose por promover liberação de $\mathrm{GH}$, com antagonismo da insulina e predisposição para o desenvolvimento de diabetes [35,36].

Cerca de $70 \%$ dos proprietários relataram que suas cadelas haviam entrado no cio em até dois meses antes do diagnóstico de DM. Certos casos de DM durante o diestro podem ser resolvidos por ovariectomia antes que ocorra depleção das reservas das células beta [5,7].

Uma das pacientes recebeu o diagnóstico de diabetes e piometra ao mesmo tempo. A ovariohisterectomia não reverteu o quadro diabético, como ocorre com algumas cadelas [6]. Neste caso, houve um indício da piometra ser responsável pelo desenvolvimento de DMID. Um estudo de ligação hormônio-receptor foi realizado em amostra de tecido adiposo desta paciente em um trabalho paralelo [30], e observou-se um menor número de receptores. Assim, a resistência à insulina provocada por hormônios antagônicos, associado ao menor número de receptores, pode ter desencadeado uma depleção das células $\beta$ pancreáticas [25].

A mortalidade de quase 50\% dos cães diabéticos estudados entre 4 e 9 meses após o diagnóstico ressalta que o tratamento pode ser frustrante [34] e que os primeiros seis meses são decisivos para o controle da doença [5]. A causa da morte é decorrente de cetoacidose severa, doença intercorrente (pancreatite, insuficiência renal) ou inadequação do tratamento [26].

\section{Aspectos nutricionais}

Neste trabalho, $78 \%$ dos cães recebiam comida caseira. Dieta rica em gordura e com baixo teor de carboidratos pode predispor ao desenvolvimento da DM [14]. Cães alimentados com dietas ricas em gordura diminuem a sensibilidade periférica à insulina [18] e têm redução no transporte de insulina para o sistema nervoso central, causando inibição do centro da saciedade no hipotálamo [19] e estimulação do centro da fome [10]. A redução na captação de insulina pelo SNC é consequiência do ganho de peso [24]. Postulase que a liberação de ácidos graxos livres (AGL) reduz a captação de glicose no músculo e a secreção de insulina, ao tempo que aumenta a produção hepática de glicose [22]. Os AGL também estão associados à reduzida fosforilação de mensageiros intracelulares que resultam em menor resposta à insulina [33]. O tecido adiposo também secreta leptina, reguladora da ingestão de alimento, do gasto energético e da sensibilidade à insulina [29].
O desbalanço nutricional se agrava quando os proprietários forneciam petiscos aos animais $(79 \%$ dos casos). O fato de quase $70 \%$ dos cães estarem com excesso de peso corporal corrobora com a hipótese do envolvimento da obesidade na apresentação de DM em cães [18,21]. O bom nível de exercícios de 9 dos 14 cães diabéticos não parece ter efeito positivo contra a DM nestes casos. A falta de exercícios, obesidade e estressores ambientais são considerados importantes fatores no desenvolvimento de DM em cães [14, 27].

\section{Aspectos laboratoriais}

Os valores hematológicos não revelaram alterações nos cães afetados por diabetes. A literatura não cita grandes alterações no hemograma de pacientes com DM [5]. As principais alterações acontecem na urina e na composição química do sangue. $\mathrm{O}$ volume de urina aumenta devido à diurese osmótica promovida pela hiperglicemia [28]. A densidade urinária de cães diabéticos está acima de 1.025, devido à presença de glicosúria e proteinúria [5]. A ausência persistente de glicosúria em cães diabéticos sob terapia insulínica pode ser sinal de risco para ocorrência de hipoglicemia [40]. A presença de corpos cetônicos na urina na DM é considerada como diagnóstico de cetoacidose mas não de diabetes. A cetonúria pode ocorrer em indivíduos saudáveis em jejum [20]. A presença de glicosúria, cetonúria, bacteriúria e proteinúria associadas ou não a piúria e hematúria é comum em pacientes diabéticos [25]. Pode haver maior bacteriúria em cães com DM devido a infecções ocultas [23]. A lipúria (40\% dos casos) ocorre em doenças degenerativas dos túbulos, como acontece no DM canino [39].

Os valores de creatinina não revelaram alteração renal e apenas em $10 \%$ dos casos houve aumento na concentração de uréia, talvez devido ao estado de catabolismo protéico [9]. Estes parâmetros podem aumentar em casos de insuficiência renal e desidratação [3]. As enzimas ALT e FAS costumam estar aumentadas na DM em decorrência de lipidose hepática [5]. Neste trabalho, houve atividade elevada de FAS em $70 \%$ dos casos. Aumentos de FAS acima 500 U/l (30\% dos casos) são compatíveis com hiperadrenocorticismo concomitante [5]. A enzima GGT, indicativa de colestase [20], aumentou em 50\% dos casos. Das transaminases, enzimas indicadoras de lesão hepática, a ALT aumentou em $40 \%$ e AST em $20 \%$ dos casos estudados. Com base nesses resultados, pode-se afir- 
mar que os pacientes analisados mostraram sinais de lesão hepática, possivelmente por degeneração gordurosa, alteração comum em pacientes diabéticos [26]. A amilase pancreática não aumentou, não tendo aparente utilidade no diagnóstico de DM [38].

A hiperlipidemia clássica do DM é caracterizada por hipercolesterolemia e hipertrigliceridemia e deve-se à inadequada remoção dos quilomicrons da circulação devido à insuficiência de insulina $[8,10]$. A hiperlipidemia é um importante fator envolvido na resistência a insulina [37].

$\mathrm{O} \beta$-OH-butirato acumula-se no sangue também como consequiência da deficiência da insulina, reduzindo a utilização destes compostos como fonte de energia, mantendo-os na circulação [25]. A mensuração deste metabólito é considerada uma ferramenta potencial para o diagnóstico de cetoacidose diabética [4].

A hiperglicemia é efeito direto da deficiência de insulina para estimular a captação de glicose nas células assim como para antagonizar os efeitos do glucagon, que promove uma maior produção endógena de glicose na deficiência de insulina [10]. Neste estudo $100 \%$ dos animais apresentaram hiperglicemia, a despeito da terapia com insulina, uma vez que as coletas foram realizadas antes da aplicação de insulina pela manhã. A fructosamina se forma no sangue por ligação da glicose em excesso a resíduos de aminoácidos das proteínas plasmáticas, principalmente albumina, apresentando um importante papel no diagnóstico e monitoração do paciente diabético [17]. Neste estudo, somente $20 \%$ dos casos estudados apresentaram concentrações de fructosamina sérica dentro do normal.

\section{CONCLUSÕES}

A obesidade e a alimentação com comida caseira podem ser fatores envolvidos no desenvolvimento de DM em cães. As fêmeas são mais predispostas, assim como a raça Poodle. As principais alterações clínico-patológicas envolvem a glicosúria, hiperglicemia, hipertrigliceridemia, aumento na atividade das enzimas FAS, ALT e GGT e aumento na concentração de fructosamina sérica e de proteinas totais.

\section{NOTAS INFORMATIVAS}

${ }^{1}$ Celm CC-530, São Paulo/SP.

${ }^{2}$ Multistix, Bayer, Argentina.

${ }^{3}$ Labtest Diagnóstica S.A., Lagoa Santa/MG.

\section{REFERÊNCIAS}

1 Bastos C.V. \& Bicalho A.P. 2003. Sedimentoscopia em urinas caninas com características físico-químicas normais: qual o seu valor? Clínica Veterinária. 45: 52-56.

2 Beam S., Correa M.T. \& Davidson M.G. 1999. A retrospective-cohort study on the development of cataracts in dogs with diabetes mellitus: 200 cases. Veterinary Ophthalmology. 2: 169-172.

3 Chandler E.A. 1979. Medicina y Terapéutica Canina. Zaragoza: Acribia, 589p.

4 Duarte R., Simões D.M., Franchini M.L., Marqueze M.L. \& Ikesake J.H. 2002. Accuracy of serum beta-hydroxybutyrate measurement for diagnosis of diabetic ketoacidosis in 116 dogs. Journal of Veterinary Internal Medicine. 16: 411-417.

5 Feldman E.C. \& Nelson R.W. 2004. Canine and Feline Endocrinology and Reproduction. 3rd edn. Missouri: Saunders, 1089p.

6 Fleeman L.M. \& Rand J.S. 2000. Tratamiento a largo plazo del perro diabético. Waltham Focus. 10: 16-23.

7 Fleeman L.M. \& Rand J.S. 2001. Management of canine diabetes. Veterinary Clinics of North America: Small Animal Practice. 31: 855-879.

8 Ford R.B. 1997. Hiperlipidemia canina. In: Ettinger S.J \& Feldman E.C. (Eds). Tratado de Medicina Interna Veterinária. v.2. 4.ed. São Paulo: Manole, pp.1957-1965.

9 Freyse E.J., Rebrin K., Petrzika M. \& Fischer U. 1996. Increased urea synthesis in insulin-dependent diabetic dogs maintained normoglycemic: effect of portal insulin administration and food protein content. Diabetes. 45: 667-673.

10 Ganong W.F. 1999. Review of Medical Physiology. 19th edn. Connecticut: Lange, 781p.

11 González F.H.D., Carvalho V., Möller V.A. \& Duarte F.R. 2001. Perfil bioquímico sangüíneo de cães e gatos na cidade de Porto Alegre, Rio Grande do Sul, Brasil. Arquivos da Faculdade de Veterinária UFRGS. 29: 1-6.

12 Greco D.S. 2001. Diagnosis and treatment of juvenile endócrine disorders in puppies and kittens. Veterinary Clinics of North America: Small Animal Practice. 31: 401-407.

13 Greco D.S. 2001. Diagnosis of diabetes mellitus in dogs. Veterinary Clinics of North America: Small Animal Practice. 31: 844-853 
14 Guptill L., Glickman L. \& Glickman N. 2003. Time trends and risk factors for diabetes mellitus in dogs: analysis of veterinary medical data base records. The Veterinary Journal. 165: 240-247.

15 Hess R.B., Kass P.H. \& Ward C.R. 2000. Breed distribution of dogs with diabetes mellitus admitted to a tertiary care facility. Journal of American Veterinary Medical Association. 216: 1414-1417.

16 Hoenig M. 2002. Comparative aspects of diabetes mellitus in dogs and cats. Molecular and Cellular Endocrinology. 197: 221-229.

17 Jensen A.L. 1995. Glycated blood proteins in canine diabetes mellitus. Veterinary Record. 137: 401-405.

18 Kaiyala K.J., Prigeon R.L., Kahn S.E., Woods S.C., Porte T. \& Schwartz M.W. 1999. Reduced $\beta$-cell function contributes to impaired glucose tolerance in dogs made obese with a high-fat feeding. American Journal of Physiology. 277 : E659-E667.

19 Kaiyala K.J., Prigeon R.L., Kahn S.E., Woods S.C. \& Schwartz M.W. 2000. Obesity induced by a high-fat diet is asscociated with reduced brain insulin transport in dogs. Diabetes. 49: 1525-1533.

20 Kaneko J.J., Harvey J.W. \& Bruss M.C. 1997. Clinical Biochemistry of Domestic Animals. 5th edn. Missouri: Academic Press, 932p.

21 Mattheeuws D., Rottiers M.D., Kaneko J.J. \& Vermeulen M.D. 1984. Diabetes mellitus in dogs: relationship of obesity to glucose tolerance and insulin response. American Journal of Veterinary Research. 45: 98-103.

22 McGarry J.D. 2002. Dysregulation of fatty acid metabolism in the etiology of tipe 2 diabetes. Diabetes. 51: 7-18.

23 McGuire M.C., Schulman R., Ridgway M.D. \& Bollero G. 2002. Detection of occult urinary tract infections in dogs with diabetes mellitus. Journal American Animal Hospital Association. 38: 541-544.

24 McMinn J.E., Baskin D.G. \& Schwartz M.W. 2000. Neuroendocrine mechanisms of regulating food intake and body weight. Obesity Reviews. 1:37-46.

25 Nelson R.W. 1997. Diabete melito. In: Ettinger S.J. \& Feldman E.C. (Eds). Tratado de Medicina Interna Veterinária. v. 2. 4. ed. São Paulo: Manole, pp.2085-2122.

26 Nelson R.W. 2003. Disorders of the endocrine pancreas. In: Nelson R.W. \& Couto C.G. (Eds). Small Animal Internal Medicine. 3rd. edn. St Louis: Mosby, pp.729-778.

27 Neuvians T.P. \& Berger M. 2002. Diabetes care in cats and dogs. Diabetic Medicine. 19: 77-79.

28 Nichols R. 2001. Polyuria and polydipsia. Veterinary Clinics of North America: Small Animal Practice. 31: 833-843.

29 Pirola L., Johnston A.N. \& Van Obberghen E. 2004. Modulation of insulin action. Diabetologia. 47: 170-184.

30 Pöppl A.G., Trapp M., Lorandi A.L., Ligocki G.L., Uez F., Assis L., Silva R.S.M. \& Kucharski L.C. 2004. Utilização da técnica de binding para avaliar o receptor de insulina em tecido adiposo de cães diabéticos. In: Anais do XVI Congresso Estadual de Medicina Veterinária (Passo Fundo, Brasil). Sociedade de Veterinária do Rio Grande do Sul. CD-ROM.

31 Renauld A., Gomez N.V., Scaramal J.D., Garrido D. \& Wanke M.M. 1998. Natural estrous cycle in normal and diabetic bitches. Basal serum total lipids and cholesterol. Serum tryglicerides profiles during glucose and insulin tests. Acta Physiologica Pharmacologica et Therapeutica Latino Americana. 48: 41-51.

32 Rijnberk A., Kooistra H.S. \& Mol J.A. 2003. Endocrine diseases in dogs and cats: similarities and differencas with endocrine diseases in humans. Growth Hormone and IGF Reasearh. 13: S158-S164.

33 Saltiel A.R. \& Kahn C.R. 2001. Insulin signalling and the regulation of glucose and lipid metabolism. Nature. 414: $799-806$. 34 Schulman R.L. 2003. Insulin and other therapies for diabetes mellitus. Veterinary Medicine. April: 334-347.

35 Selman P.J., Mol J.A., Rutteman G.R. \& Rijnberk A. 1994. Progestin treatment in the dog I. Effects on growth hormone, insuli-like growth factorI and glucose homeostasis. European Journal of Endocrinology. 131: 413-421.

36 Selman P.J., Mol J.A., Rutteman G.R. \& Rijnberk A. 1994. Progestin treatment in the dog II. Effects on the hipothalamicpituitary-adrenocortical axis. European Journal of Endocrinology. 131: 422-430.

37 Shaepherd P.R. \& Kahn B.B. 1999. Glucose tranporters and insulin action. The New England Journal of Medicine. 341:248-257.

38 Steiner J.M. \& Williams D.A. 1999. Feline exócrine pancreatic disorders. Veterinary Clinics of North America: Small Animal Practice. 29: 551-568.

39 Thrall M.A. 2004. Veterinary Hematology and Clinical Biochemistry. Maryland: Lippincott Williams \& Wilkins, 518p.

40 Whitley N.T., Drobatz K.J. \& Panciera D.L. 1997. Insulin overdose in dogs and cats: 28 cases (1986-1993). Journal of American Veterinary Medical Association. 211: 326-330.

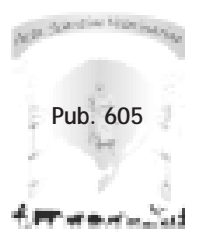

